\title{
ARE ADVANCED WASTEWATER TREATMENT TECHNOLOGIES A SOLUTION FOR TOTAL REMOVAL OF MICROPLASTICS IN TREATED EFFLUENTS?
}

\author{
SONIA OLMOS, JOAQUÍN LÓPEZ-CASTELLANOS \& JAVIER BAYO \\ Department of Chemical and Environmental Engineering, Technical University of Cartagena, Spain
}

\begin{abstract}
The presence of microplastics (MP) in water environments is considered a global threat, with different adverse effects on ingesting organisms: physical damage due to the plastic particles themselves, leaching of some constituent monomers, the potential transport of organic and inorganic pollutants, and leaching of additives used in the manufacture and polymerisation of plastic products. In the last case, especially when additives are not chemically bound to the polymer structure, they may leach out into the aquatic environment. This paper deals with the role of wastewater treatment plants (WWTP) as sources of microplastics to the environment, and the efficiency of different advanced technologies used for wastewater treatment aiming towards a zero pollution discharge. The monitoring study was carried out during 2018, including three different wastewater treatments, i.e. activated sludge process with extended aeration (ASP), rapid sand filtration (RSF), and membrane bioreactor (MBR). Microplastics comprised an average value of $45.0 \%$ total microlitter (ML), with average concentrations decreasing after each wastewater treatment step. The decrease of microplastics from the primary to the final effluent was $90.2 \%$ for ASP, $93.8 \%$ for RSF, and $96.2 \%$ for MBR, indicating the importance of final-stage or tertiary technologies to remove this emerging pollutant, although never reaching a zero pollution discharge. The main plastic polymer found in all wastewater samples was low-density polyethylene (LDPE), followed by polypropylene (PP), high-density polyethylene (HDPE), and textile fibres made of nylon (NYL). Five shapes were detected, i.e. fragments, films, beads, fibres, and foam. Films decreased from primary to final effluent, conversely to fragments that increased during the sewage treatment.
\end{abstract}

Keywords: microplastics, rapid sand filtration, activated sludge process with extended aeration, membrane bioreactor.

\section{INTRODUCTION}

The global annual production of plastics was around 335 million tonnes for 2016, 4.03\% higher than in 2015, and it can be attributed to: polypropylene (PP) $19.3 \%$, low density polyethylene (LDPE) 17.5\%, high density polyethylene (HDPE), polyvinyl chloride (PVC) $10 \%$, polyurethane (PUR) 7.5\%, polyethylene terephthalate (PET) $7.4 \%$, and polystyrene (PS) $6.7 \%$ [1].

Plastics are made of polymers, long and flexible chain molecules formed after reaction of smaller ones called monomers [2], and whose properties are adjusted by means of additives. These additives, i.e. lubricants, fire retardants, emulsifiers, plasticizers, adhesives, and so on, may leach from plastic materials, with environmental effects not easy to assess [3]. Fragmentation of large plastic debris into smaller ones takes place in the environment, due to physical, biological and chemical mechanisms, with chemical and mechanical weathering the most important ones, originating the term "microplastics", used for plastics smaller than $5 \mathrm{~mm}[4]$.

This paper describes the efficiency of different advanced technologies used for wastewater treatment aiming towards a zero pollution discharge for microplastics. It is well known that wastewater treatment plants, together with the urban runoff process, can be one 
of the most important pathways of environmental pollution by microplastics [5], not only through treated water, but also through the sludge [6].

\section{MATERIALS AND METHODS}

\subsection{Sample processing}

A total of 103,205 L of water were processed for this study, carried out from February 2018 to July 2018. Samples were collected before and after the activated sludge process with extended aeration, rapid sand filtration, and membrane bioreactor, located in Cabo de Palos and Águilas, two cities belonging to the Region of Murcia (southeast of Spain). Table 1 displays the main characteristics of both WWTP. All samples were collected in glass containers, in order to avoid additional contamination, and kept refrigerated at $4^{\circ} \mathrm{C}$ on arrival to the laboratory. Microparticles were extracted from wastewater samples by means of a concentrated sodium chloride solution $\left(\mathrm{NaCl} ; 120 \mathrm{~g} \cdot \mathrm{l}^{-1}\right)$, as previously indicated by Bayo et al. [6], resulting in a supernatant with floating particles, that were filtered through a Whatman filter paper $(0.45 \mu \mathrm{m})$. After washing this filter with bi-distilled water and drying on an air-forced stove, microparticles were processed by microscopic and Fourier-transform infrared spectroscopy (FTIR) analyses.

Table 1: Main characteristics of WWTP.

\begin{tabular}{|l|l|c|c|c|c|}
\hline WWTP & $\begin{array}{l}\text { Geographic } \\
\text { situation (UTM) }\end{array}$ & Municipality & WF $\left(\mathrm{m}^{3} \mathrm{~d}^{-1}\right)$ & Technology & Effluent \\
\hline $\begin{array}{l}\text { Cabo de } \\
\text { Palos }\end{array}$ & $\begin{array}{l}\text { UTMX: } 700578 \\
\text { UTMY: } 4166392\end{array}$ & $\begin{array}{c}\text { Cartagena } \\
\text { and San } \\
\text { Javier }\end{array}$ & 50,000 & ASP & Irrigation \\
\hline Águilas & $\begin{array}{l}\text { UTMX: } 625665 \\
\text { UTMY: } 4143001\end{array}$ & Águilas & 8,000 & $\begin{array}{c}\text { RSF } \\
\text { MBR }\end{array}$ & Irrigation \\
\hline
\end{tabular}

ASP: activated sludge process with extended aeration; MBR: membrane bioreactor; RSF: rapid sand filtration; WF: water flow.

\subsection{Contamination prevention}

Because of plastic is used in a wide range of sectors and products, it was necessary to take a series of measures to prevent pollution, i.e.:

- Samples were collected in glass containers with metal lid.

- Use of cotton gown and nitrile gloves in all extraction processes [7].

- Use of glass and/or metal laboratory utensils.

- Cleaning of the laboratory material used, as well as Petri dishes used for transport and storage [8], with isopropyl alcohol.

In spite of all the measures taken and since other sources of contamination are more difficult to avoid, a target was made to rule out the influence of contamination on our data [9], [10].

\subsection{Microparticle analyses}

Microscopic analyses were carried out with an Olympus SZ61 trinocular microscope (Olympus Co., Tokyo, Japan), providing a superior image quality with a $10^{\circ}$ convergence 
angle at a working distance of $110 \mathrm{~mm}$, magnification range from $6.7 \mathrm{x}$ to $45 \mathrm{x}$ and LED lighting. This trinocular microscope was coupled with an Olympus Altra 20 high resolution digital camera, with a maximum resolution of $1596 \times 1196$ pixels, 10 bits per color channel, 7.5 frames per second at full resolution, and $0.1 \mathrm{~ms}$ to $1 \mathrm{~s}$ exposure time. The infrared spectra were acquired with a Thermo Nicolet 5700 Fourier transformed infrared (FTIR) spectrometer (Thermo Nicolet Analytical Instruments, Madison, WI, USA), provided with a deuterated triglycine sulfate (DTGS) detector and $\mathrm{KBr}$ detector. The spectra collected were an average of 20 scans with a resolution of $16 \mathrm{~cm}^{-1}$ in the range of $4000-400 \mathrm{~cm}^{-1}$. Spectra were controlled and evaluated by the OMNIC software package, by means of different reference spectra databases, where peak maxima were manually determined after examination of absorbance values.

\section{RESULTS AND DISCUSSION}

\subsection{General results}

A total of 167 microparticles were analysed in this study, all of them smaller than or equal to $5 \mathrm{~mm}$ in diameter. After examination through the stereomicroscope, each identified particle was subjected to infrared analysis. This technique was used as the fundamental objective of this paper was to deal with the role of wastewater treatment plants (WWTP) as sources of microplastics to the environment, thus avoiding false positives that, in our opinion, other authors have been able to include in their counts, by using visualization through an optical microscope as the only method for microplastic identification [11]. In addition, this technique makes it possible to differentiate such striking tonalities as those shown in Fig. 1.

The use of the stereomicroscope allowed a more exhaustive classification according to the shape of microplastics, with the films being the most recurrent forms $(67.0 \%)$, followed by fragments $(20.0 \%)$, beads $(8.0 \%)$, fibres $(4.0 \%)$ and finally, foams $(1.0 \%)$, as depicted in Fig. 2. Films decreased from primary to final effluent, conversely to fragments that increased during the sewage treatment.

In relation to plastic polymers, the most usual one was low-density polyethylene (LDPE) with $1.6 \pm 1.0 \mathrm{MP} \mathrm{l}^{-1}$, followed by polypropylene (PP) with $0.3 \pm 0.2 \mathrm{MP}^{-1}$, high-density polyethylene (HDPE) with $0.2 \pm 0.1 \mathrm{MP}^{-1}$, and textile fibres made of nylon (NYL) with $0.1 \pm 0.1 \mathrm{MP}^{-1}$. Table 2 shows type of polymers included in each one of the four main families isolated.

HDPE, PP and NYL microplastics were completely removed in the WWTP with ASP technology. However, only $11 \%$ of microplastics made of LDPE were removed in the same WWTP. Single-use plastic carrier bags, of which free distribution has been recently banned in Spain, together with plastic film waste from agriculture greenhouses close to the treatment plant, could be the main sources responsible for these results, because of open-aired secondary clarifiers.

The same results could be observed for RSF technology, although LDPE microplastics were removed in a higher percentage than those removed by ASP, i.e. $84.9 \%$ compared to $11 \%$.

MP polymers isolated in this study match with the most polymer types used by European plastic converters in 2016 [1], mainly represented by PP (19.3\%), LDPE (17.5\%), and HDPE $(12.3 \%)$. 

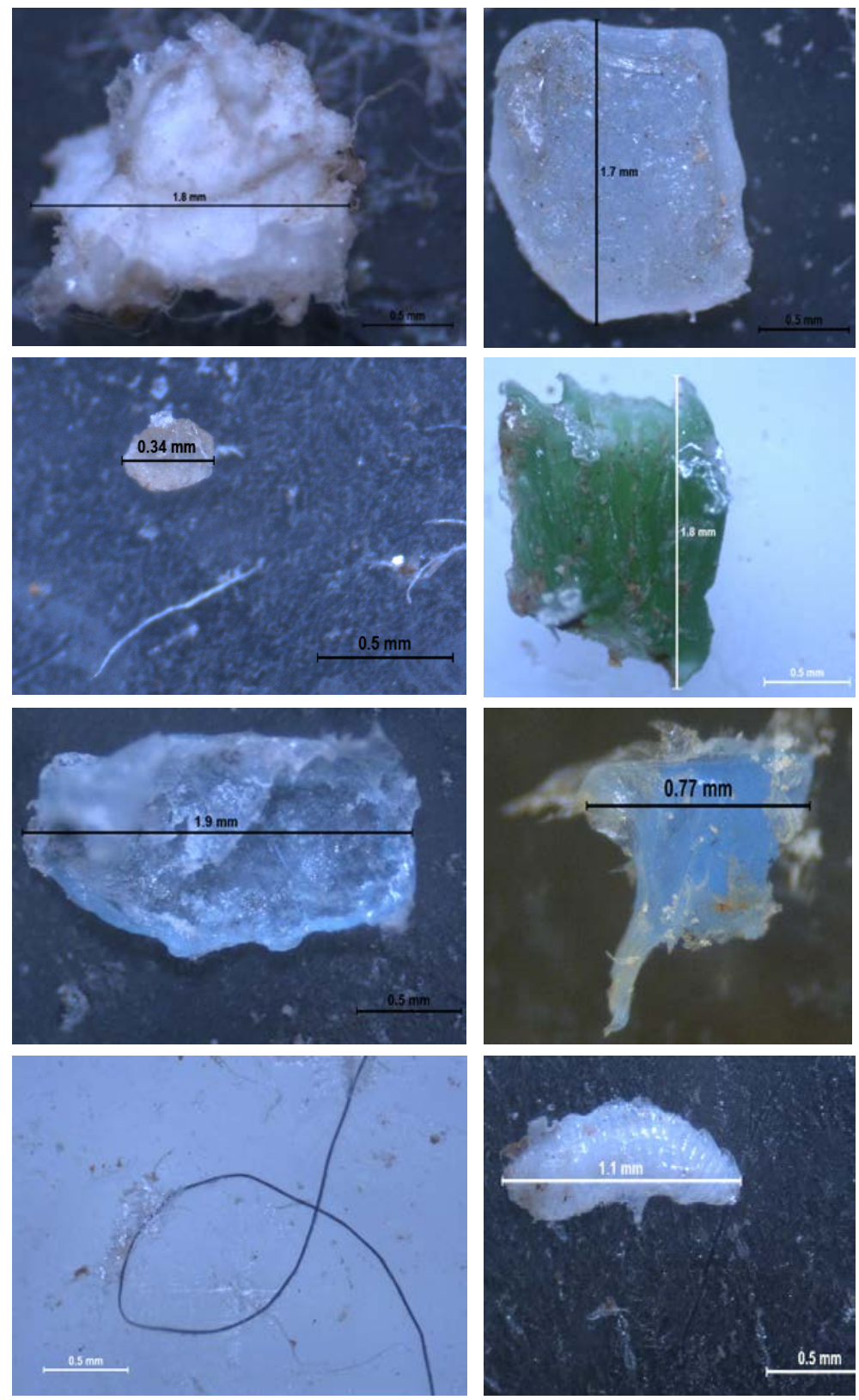

Figure 1: Microscopic images of microplastics found in wastewater treatment plants. 


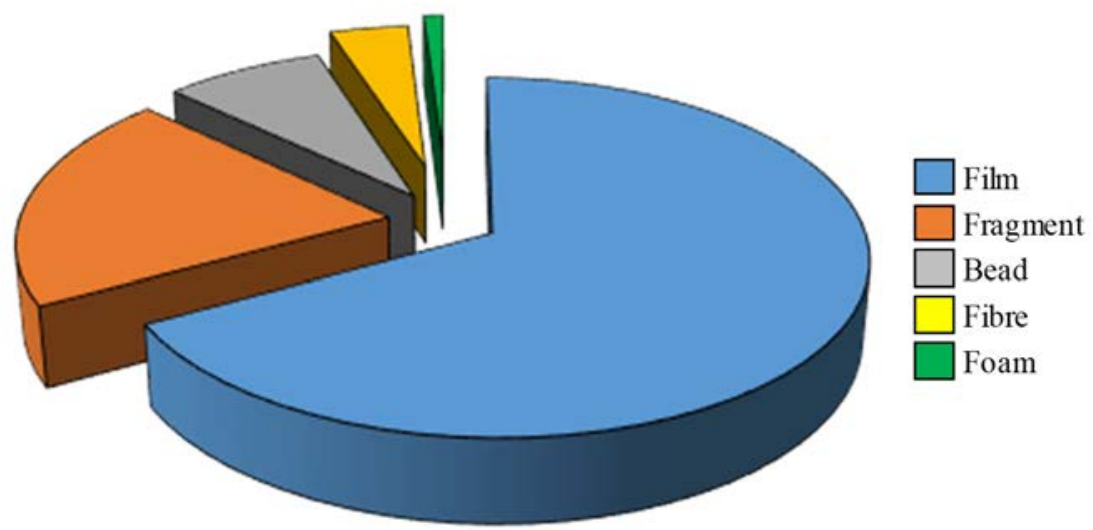

Figure 2: Main forms isolated in wastewater treatment plants.

Table 2: Polymers included in each one of the four main family types isolated in wastewater samples.

\begin{tabular}{|c|c|}
\hline Family & Polymers included \\
\hline HDPE & $\begin{array}{l}\text { Ethene homopolymer \#2; polyethylene; polyethylene chlorinated; } \\
\text { polyethylene oxidized; poly(ethylene) }(\mathrm{n}=180 \mathrm{cps})\end{array}$ \\
\hline LDPE & Low-density polyethylene; polyethylene wax \#2 \\
\hline NYL & $\begin{array}{l}\text { Nylon (polyamide) } 12 \text { (Grilamid }^{\circledR} \text { TR 55); polyamide nylon 6/12 }\left(\text { Grilamid }^{\circledR}\right) \\
\text { polyamide resin; poly(4-methylcaprolactam); polyamide-nylon } 6 / 6(\mathrm{TP})\end{array}$ \\
\hline PP & $\begin{array}{l}\text { Polypropylene; polypropylene }+ \text { Vistalon }^{\mathrm{TM}} \text {; polypropylene }+20 \% \text { talcum; } \\
\text { polypropylene copolymer }\end{array}$ \\
\hline
\end{tabular}

HDPE: high-density polyethylene; LDPE: low-density polyethylene; NYL: nylon; PP: polypropylene.

\subsection{Presence and evolution of microplastics in WWTP}

Fig. 3 shows the evolution of all MP identified in the activated sludge process with extended aeration (ASP), rapid sand filter (RSF), and membrane bioreactor (MBR) technologies. The average concentrations of particulate forms per litre of sampled wastewater were $2.23 \pm 0.10$ and $0.22 \pm 0.09$, for the primary and the final effluent, respectively. These outcomes proved a statistically significant and efficient removal of these micropollutants through the WWTP, accounting for a $90.2 \%(t$-student $=20.097, \mathrm{p}<0.01)$. This is the most widely used treatment technology in our region, because of its low installation cost, low land requirement, and good quality effluent, among others. In our study, this simple technology gave the lowest percentage of MP removal, lower than that reported by Murphy et al. [7] in a secondary WWTP located in Glasgow (98.41\%) but higher than that reported by Ziajahromi et al. [12] with an average of 1.54 and $0.28 \mathrm{MP}^{-1}$ in the primary and tertiary treated effluent, respectively. On the other hand, the low overall retention of MP in WWTP can be attributed to the MP remaining or passing from the sludge line, not being completely eliminated from the water line [6]. 


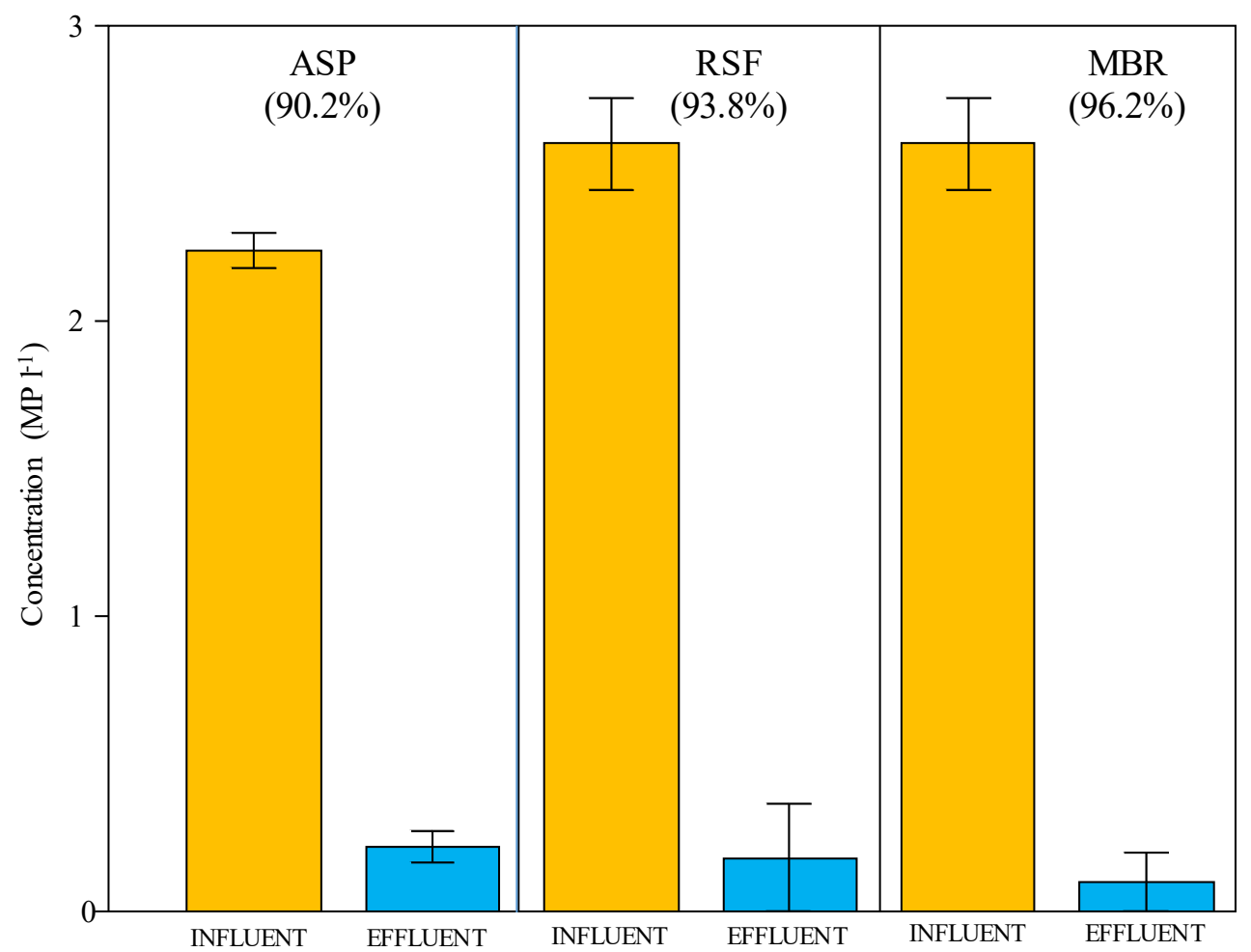

Figure 3: Microplastics evolution through the activated sludge process with extended aeration (ASP), rapid sand filter (RSF), and membrane bioreactor (MBR) (error bars represent standard error).

The removal of MP particles through the rapid sand filtration (RSF) technology proved to decrease from an average influent concentration of $2.53 \pm 0.23 \mathrm{MP}^{-1}$ down to an average effluent concentration of $0.16 \pm 0.25 \mathrm{MP} \mathrm{1}^{-1}$. These outcomes proved a statistically significant removal of these microparticles through the WWTP, accounting for a $93.8 \%$ ( $t$-student $=$ $51.476, \mathrm{p}<0.001)$. As reported by Talvitie et al. [13], MP are caught among sand grains or adhered to their surface, and their removal could be possibly improved by the use of coagulants and flocculants. The removal percentage reported by these authors for a RSF was $97.1 \%$.

The results for the MBR technology (Fig. 3) showed a statistically significant removal of $96.2 \%$ (t-student $=10.342, p<0.01$ ), with an average influent concentration of $2.60 \pm 0.27 \mathrm{MP} \mathrm{l}^{-1}$ and an average effluent concentration of $0.10 \pm 0.17 \mathrm{MP} \mathrm{l}^{-1}$. Surprisingly, membrane bioreactor technology treated the highest MP concentration in the influent, compared to other technologies, reaching also the highest removal percentage. Beside this, the vast majority of MP found after the MBR technology was fibres. Mintenig et al. [14] showed that after a tertiary post-filtration with 12 rolling filters completely removed MP $>500 \mu \mathrm{m}$, and synthetic fibres by a $93 \%$.

In summary, municipal WWTPs represent a sink but also a source of MP to enter into the aquatic and soil environment. Wastewater treatment facilities are not designed to remove emerging pollutants like MP [15], and the release of MP from personal care products and 
fabrics should be considered as an important pathway for MP contamination, besides other significant pathways like urban runoff or wind-blown debris from plastic fragmentation.

\section{CONCLUSIONS}

This paper deals with the role of WWTP as sources of microplastics to the environment, and the efficiency of different advanced technologies used for wastewater treatment aiming towards a zero pollution discharge. The monitoring study was carried out during February 2018 and July 2018, including three different wastewater treatments, i.e. activated sludge process with extended aeration (ASP), rapid sand filtration (RSF), and membrane bioreactor (MBR). Microplastics comprised an average value of $45.0 \%$ total microlitter, with average concentrations decreasing after each wastewater treatment step. It is well known these wastewater treatment plants, together with the urban runoff process, can be one of the most important pathways of environment pollution by microplastics, not only through treated water, but also through sludge. Our results indicated a significant decrease of all these microplastics through different processes. The decrease of microplastics from the primary to final effluent was $90.2 \%$ for ASP, $93.8 \%$ for RSF, and $96.2 \%$ for MBR, indicating the importance of final-stage or tertiary technologies to remove this emerging pollutant, although never reaching a zero pollution discharge. Low and high density polyethylene was the main plastic polymer type, being the most demanded plastic in the world together with polypropylene. Five different shapes were detected, i.e. fragments, films, beads, fibres, and foam. Films decreased from primary to final effluent, conversely to fragments that increased during the sewage treatment.

\section{ACKNOWLEDGEMENTS}

Analyses carried out by S. Olmos were supported by a grant from Fundación Séneca (20268/FPI/17). The authors would like to extend their thanks to the crew from the wastewater treatment plant of Cabo de Palos and Águilas for their assistance with sample collection.

\section{REFERENCES}

[1] Plastics - the Facts 2017. An analysis of European plastics production, demand and waste data. www.plasticseurope.org/download_file/view/477/179. Accessed on: 7 Feb. 2018.

[2] Ruzette, A.V. \& Leibler, L., Block copolymers in tomorrow's plastics. Nature Materials, 4(1), pp. 19-31, 2005.

[3] Pires, A., Martinho, G., Ribeiro, R., Mota, M. \& Teixeira, L., Extended producer responsibility: a differential fee model for promoting sustainable packaging. Journal of Cleaner Production, 108, pp. 343-353, 2015.

[4] Bayo, J., Guillén, M., Olmos, S., Jiménez, P., Sánchez, E. \& Roca, M.J., Microplastics as vector for persistent organic pollutants in urban effluents: The role of polychlorinated biphenyls. International Journal of Sustainable Development and Planning, 13(4), pp. 671-682, 2018.

[5] Eerkes-Medrano, D., Thompson, R.C. \& Aldridge, D.C., Microplastics in freshwater systems: A review of the emerging threats, identification of knowledge gaps and prioritisation of research needs. Water Research, 75, pp. 63-82, 2015.

[6] Bayo, J., Olmos, S., López-Castellanos, J. \& Alcolea, A., Microplastics and microfibers in the sludge of a municipal wastewater treatment plant. International Journal of Sustainable Development and Planning, 11(5), pp. 812-821, 2016. 
[7] Murphy, F., Ewins, C., Carbonnier, F. \& Quinn, B., Wastewater treatment works (WwTW) as a source of microplastics in the aquatic environment. Environmental Science and Technology, 50(11), pp. 5800-5808, 2016.

[8] Rocha-Santos, T. \& Duarte, A.C., A critical overview of the analytical approaches to the occurrence, the fate and the behavior of microplastics in the environment. TrAC Trends in Analytical Chemistry, 65, pp. 47-53, 2015.

[9] Magnusson, K. \& Norén, F., IVL Swedish Environmental Research Institute. Screening of Microplastic Particles in and Down-Stream a Wastewater Treatment Plant, 2014.

[10] Imhof, H., Jschmid, J., Niessner, R., Ivleva, N.P. \& Laforsch, C., A novel, highly efficient method for the quantification of plastic particles in sediments of aquatic environments. Limnology and Oceanography: Methods, 10, pp. 524-537, 2012.

[11] Estahbanati, S. \& Fahrenfeld, N.L., Influence of wastewater treatment plant discharges on microplastic concentrations in surface water. Chemosphere, 162, pp. 277-284, 2016.

[12] Ziajahromi, S., Neale, P.A., Rintoul, L. \& Leusch, F.D., Wastewater treatment plants as a pathway for microplastics: Development of a new approach to sample wastewaterbased microplastics. Water Research, 112, pp. 93-99, 2017.

[13] Talvitie, J., Mikola, A., Setala, O., Heinonen, M. \& Koistinen, A., How well is microlitter purified from wastewater? A detailed study on the stepwise removal of microlitter in a tertiary level wastewater treatment plant. Water Research, 109, pp. 164-172, 2017.

[14] Mintenig, S.M., Int-Veen, I., Loder, M.G., Primpke, S. \& Gerdts, G., Identification of microplastic in effluents of waste water treatment plants using focal plane array-based micro-Fourier-transform infrared imaging. Water Research, 108, pp. 365-372, 2017.

[15] Mason, S., Garneau, D., Sutton, R., Chu, Y. \& Ehmann, K., Microplastic pollution is widely detected in US municipal wastewater treatment plant effluent. Enviromental Pollution, 218, pp. 1045-1054, 2016. 